\title{
Elites Gaúchas e Formas de Dominação: Disputas da Modernização Agrária
}

\author{
Elites Gauchas y Formas de Dominación: Disputas de la \\ Modernización Agraria \\ Gaucho Elites and Forms of Domination: Disputes Over Agrarian \\ Modernization
}

\author{
Josué Kuhn Völz1 \\ Pedro Henrique de Oliveira ${ }^{23}$
}

\begin{abstract}
Resumo
Levando em conta os entraves sociopolíticos e os processos históricos de transformação vivenciados nos pampas gaúchos, o presente trabalho buscará analisar o período correspondente a "modernização conservadora" de seu sistema agrário. Marcadamente, dois momentos - a Colonização e o pós segunda Guerra Mundial - serão centrais para o estabelecimento de determinadas praticas agrárias e sua valorização no campo do conhecimento local. Entretanto, há enfoque na formação e nas estratégias de reprodução de assimetrias de poder promovidas por um extrato da sociedade, a dizer, as elites locais - de diferentes, porém homólogos, campos de capital. Para tal, será feito uso das ferramentas metodológicas delineadas por Pierre Bourdieu, em diálogo com o arcabouço teórico identificado como Pós-colonial. Conjuntamente, se argumenta que o pacote técnico aplicado nos sistemas agrários, mais especificamente o que busca promover o "desenvolvimento", encontra suporte na diferença de valor inerente ao capital cultural importado de metodologias eurocêntricas. O que, por sua vez, encontra suporte na abordagem Decolonial acerca da geopolítica do conhecimento.
\end{abstract}

Palavras-Chave: Elites Agrárias Gaúchas; Modernização Conservadora; Pierre Bourdieu; Sistema Agrário nos Pampas; Teoria Decolonial.

\section{Resumen}

Teniendo en cuenta las peleas sociopolíticas y los procesos históricos de transformación vivenciados en los pampas gauchos, el presente trabajo buscará analizar el período correspondiente a la "modernización conservadora" de su sistema agrario. Marcadamente, dos momentos - la Colonización y la Según Guerra Mundial - serán centrales para el establecimiento de determinadas prácticas agrarias y su valorización en el campo del conocimiento local. Sin embargo, hay enfoque en la formación y en las estrategias de reproducción de asimetrías de poder promovidas por un extracto de la sociedad, a decir, las elites locales - en diferentes, pero homólogos, campos de capital. Para ello, se hará uso de las herramientas metodológicas delineadas por Pierre Bourdieu, en diálogo con el marco teórico identificado como Poscolonial.Conjuntamente, se argumenta que el paquete técnico aplicado en los sistemas agrarios, más específicamente el que busca promover el "desarrollo", encuentra soporte en la diferencia de valor inherente al capital cultural importado de metodologías eurocéntricas. Lo que, a su vez, encuentra soporte en el enfoque Decolonial sobre la geopolítica del conocimiento.

Palabras Clave: Elites Agrarias Gauchas; Modernización Conservadora; Pierre Bourdieu; Sistema Agrario en las Pampas; Teoría Decolonial.

\footnotetext{
1Bacharel em Relações Internacionais; Universidade Federal de Pelotas; Pelotas, Rio Grande do Sul, Brasil; josuekvolz@gmail.com

2Mestrando em Ciência Política; Universidade Federal de Pelotas; Pelotas; Rio Grande do Sul, Brasil; pedrohsdeoliveira27@gmail.com

30 presente trabalho foi realizado com apoio da Coordenação de Aperfeiçoamento de Pessoal de Nível Superior

- Brasil (CAPES) - Código de Financiamento 001
} 


\begin{abstract}
Taking into consideration the sociopolitical barriers and the historical transformations in the gaucho's pampas, this paper has as its goal the analysis of the time known as "conservative modernization" of its agrariam system. Notably, two distinct moments - the colonization and the post-World War II - are considered the focus for the naturalization of certain agrarian practices and theirs valorization in the local field of knowledge. However, there is a special focus in the formation and the reproduction of the strategies used by and extract of society, the local elites - belonging to different, and yet homologous, fields. To do as such, it will be employed the methodological tools created by Pierre Bourdieu together with the theoretical framework the post-colonial theories.It is central to the argument of the paper that the technical package employed in the agrarian systems, more specifically those that look to promote the "development discourse", finds basis in the inherent difference between cultural capitals due its Eurocentric roots. Such argument finds its theorical basis on the decolonial approach of the geopolitics of knowledge.
\end{abstract}

Keywords: Conservative Modernization, Decolonial Theory. Gaucho Agrarian Elites; Pampiam Agrarian System; Pierre Bourdieu;

\title{
1. Introdução
}

O presente artigo se configura como um esforço inicial para a compreensão sobre as elites agrárias na região sul do Rio Grande do Sul e sua relação com a produção de conhecimento. Abordando a legitimação desse como técnico cientifico e neutro, enquanto um claro alinhamento epistemológico com o cânone eurocêntrico se demonstra como princípio de legitimação.

Quijano (2005) aponta que o atual padrão de poder mundial é composto a partir do conjunto capitalismo, eurocentrismo e colonialismo. O último faz-se central para estabelecer a raça como um dos principais referenciais das diversas relações de poder, tanto na distribuição internacional do trabalho, como na hierarquização entre culturas. Estabelece-se a Europa como centro, imputando ao resto do globo o lugar de oposto. As dualidades primitivo/civilizado, mítico/científico, irracional/racional, tradicional/moderno surgem a partir desse intrincado movimento (Ibidem). Desse modo, a epistemologia eurocêntrica assume o posto de paradigma hegemônico através da subordinação do conhecimento concebido em outras áreas geo-históricas e outros sujeitos que não os europeus.

Para além, leva-se em consideração que o entendimento de ciência moderna foi gestada no Ocidente europeu e que sua própria legitimação universal foi possibilitada pela imposição do poder colonial. Até mesmo a expansão Europeia é possibilitada pelo mito da modernidade: de que faz-se necessário atingir o progresso através de determinada razão científica. Também pode se questionar a universalidade de qualquer conhecimento, levando em conta que o contexto determina a percepção do que é inteligível e válido intelectualmente (QUIJANO, 2005. MIGNOLO, 2005. SANTOS e MENESES, 2010). Ou seja, cada epistemologia está ligada aos atores e práticas sociais que a produz. Ocultar esse aspecto da 
ciência moderna só foi possível devido à supressão e marginalização de outros conhecimentos. Tendo sido o colonialismo e o capitalismo modernos ativos na intervenção política, econômica e militar que hierarquizou os povos e as culturas (SANTOS, MENEZES e NUNES, 2004).

Partindo-se dos esforços de Pierre Bourdieu sobre os estudos de elites, o artigo considera o conhecimento como um campo autônomo que possui como habitus cristalizado o alinhamento com os conhecimentos europeus em detrimento dos saberes locais. É importante ressaltar as diferenças entre as origens dos grupos dirigentes entre França e o Brasil para se realizar uma metodologia de pesquisa apropriada. Enquanto a França nunca possuiu escravidão em seu âmago, o Brasil a encontra como o gênese de sua estruturação social (SOUZA, 2017). Devido a essa diferença fulcral se realiza uma adaptação das teorias do autor francês com a de autores decoloniais, devido a sua compreensão única dos legados do colonialismo nos países latino americanos.

Uma vez elaborado o diálogo teórico a análise do artigo conceitua e elabora sobre os pampas como um bioma e uma arena de disputas sociais. Por fim o trabalho se configura numa análise das elites agrárias pampeanas e sua relação com os saberes locais e com o conhecimento europeu durante a chamada "Revolução Verde".

\section{As elites do conhecimento e as sociedades colonizadas: um diálogo teórico}

Em sua obra "A nobreza do Estado", de 1996, Pierre Bourdieu discorre sobre a natureza das estruturas da ordem social, colocando ênfase especial na disputa pelas posições dominantes como principal fator estruturante de uma sociedade. O campo do poder, segundo Bourdieu, consiste em um campo de forças que é constituído através da relação das diversas formas de poder e capitais diferentes, e todos os agentes e instituições buscam utilizar tais recursos através de estratégias destinadas a conservar, ou a transformar as relações de força que o constitui (DE SAINT-MARTIN, 2008).

O campo do poder compõe um sistema relativamente fechado e estático, onde diferentes subsistemas se imbricam, parecendo impossível fragmentá-lo. Porém, pelo menos dentro da sociedade francesa, nunca existiu um campo de poder autônomo, os conflitos entre grupos dirigentes seguidamente dizem respeito às atribuições e às respectivas competências de uns e de outros ( DE SAINT-MARTIN, 2008).

O poder, segundo a concepção bourdiana, existe apenas numa dimensão relacionável, não há uma concepção absoluta, o que existe são apenas recursos socialmente valorizados. Devido a essa característica relacionável do poder, para a realização da manutenção de sua 
posição dentro da estrutura, uma das principais ferramentas empregadas pelos grupos dirigentes consiste na capacidade de converter recursos entre diversos campos. Ainda, os mesmos buscam deter em abundância aspectos valorizados socialmente, ao menos o suficiente para ocuparem posições dominantes (BOURDIEU, 1996).

Tais recursos, para o autor francês, são denominados "capitais", e suas diferentes espécies - tais como titulação acadêmica, capital econômico e prestígio social - consistem em poderes específicos atuantes em diversos campos, saídos dos processos de diferenciação e automização. As diversas disputas dentro do campo do poder não visam a acumulação, ou o monopólio de uma espécie particular de capital (ou poder), mas, sim, a determinação do valor das forças relativas capazes de serem exercidas em diferentes campos. O autor (1996) descreve como "o poder sobre os diferentes poderes é o capital que confere um poder sobre o capital” (BOURDIEU, 1996, p. 6, tradução própria).

O capital cultural é particularmente relevante para o propósito deste trabalho, uma vez que apresenta papel fulcral dentro da teoria bourdiana, sendo responsável pela estruturação das disputas de dominação. A importância desse recurso pode ser demonstrada a partir de suas origens históricas, situando-as conjuntamente com o próprio surgimento do Estado moderno ${ }^{4}$ (BOURDIEU, 1996). Baseando-se no autor francês, Souza (2017) categoriza tal capital como responsável pela reprodução e justificativa do capitalismo. Considera-se como capital cultural tudo aquilo que é associado ao "espirito", à mente; incluindo arte, religião e conhecimento científico. Existem vários princípios em disputa, mas apenas aqueles que são promulgados pelos grupos dirigentes exitosos em suas disputas ascendem a essas categorias

Retomando, o autor, em seu método analítico, propõe a divisão de um estudo através de campos, principalmente no campo cultural e no econômico. Porém, ainda que proponha tal metodologia, Bourdieu argumenta quanto à existência de uma organização estrutural homóloga dos diversos campos, onde as elites sempre se situam no topo (BOURDIEU, 1996).

Uma vez adquiridos as diferentes espécies de capitais, os grupos dirigentes aplicam estratégias de reprodução para a manutenção de sua posição privilegiada dentro do campo do poder. É importante ressaltar que, na concepção bourdiana, tais estratégias não são frutos de um cálculo racional, ou de uma intenção estratégica intencional, mas resultantes da naturalização e socialização habituais. Tais estratégias encontram como seu princípio basilar o habitus, ou seja, as disposições sociais- tais como, esquemas de percepção, classificação e 
hábitos mentais- socialmente construídos que são compartilhadas por pessoas com trajetórias sociais parecidas.

A socialização possui espaço de destaque na teorização trabalhada, os espaços que as elites frequentam acabam por determinar espaços de elite. Dentro da sociedade francesa nenhum espaço fica mais claro que as Grand Écoles. De Saint Martin (2008) demonstra em seu artigo como o ensino superior produz e consagra identidades e grupos sociais concorrentes e complementares criando o que pode ser categorizado como uma "nobreza de estado". Tal processo é pautado principalmente através da socialização e da formação dos membros das futuras elites. Por ser um espaço reconhecido como formador de elites, as grandes écoles acabam por formar as elites futuras num sistema de reprodução que era considerado quase imutável e impermeável.

Em nível internacional, pode-se compreender que as disputas de poder simbólico, dentro do campo do conhecimento, não sejam diferentes. Bourdieu (2002) categoriza tais conflitos como uma realpolitik da razão. Assim, as noções de princípio de dominação dominante e princípio legitimo de legitimidade podem ser aplicadas para além do escopo do Estado. Pontua-se ainda, nenhuma narrativa permeia a estrutura do internacional como a da modernidade.A modernidade como narrativa universalista está intimamente conectada com a história da colonialidade. Em seu âmago, como disciplina, a narrativa eurocêntrica apresenta uma leitura incorreta quanto à própria história, situando sua origem na Grécia Antiga. Daí tece uma explanação etapista, que apresenta a Europa como origem da história e disseminadora do progresso, universal também, na medida em que posiciona as demais geolocaliades em um período temporal regresso em sua própria escala evolutiva (TORRES, 2008).

A universalização do particular atende a um proposito metateórico: o ocultamento da importância do locus geográfico para a constituição do sujeito. Em sua obra, Mignolo (2002) argumenta que é através de tal movimento que a narrativa eurocêntrica consegue alinhar as verdades locais com os supostos valores universais. Ao se aplicar uma linguagem bourdiana, pode-se observar que é através do campo do conhecimento que tanto o princípio da legitimação legítimo e o princípio da dominação dominante foram criados e reforçados durante o período colonial.

A visão bourdiana (1996) argumenta que para que os processos de dominação se cristalizarem é necessário que sejam vistos como "naturais". Seth (2013) argumenta que o cânone ocidental fora construído através de uma noção particular de racionalidade geográficamente localizada - que foi promulgada como universal, como natural. Servindo 
tanto como princípio legítimo de legitimação, quanto justificando a dominação da academia eurocêntrica sob as outras, sendo o princípio dominante de dominação. Concatenando com essa noção, Torres (2008) argumenta ser tal revelamento uma mostra da preocupação epistemológica de manutenção do projeto de civilização europeu, permeando o seu cânone, uma vez que hierarquiza os conhecimentos e aqueles não condizentes com a episteme ocidental eram relegados a uma inferioridade inerente.

Em seu trabalho, Torres (2008) discorre sobre a aversão epistemológica a rupturas a tal discurso ocidental como um resultado da colonialidade ${ }^{5}$ do Ser. Para o autor o "ser" é, na verdade, o Centro, e o "pensamento" um Pensamento Central. Tudo aquilo que desvia dessa concepção se torna o ente, o subdesenvolvido, o periférico. A própria dicotomia inerente dessa relação existe porque o "outro" só é reconhecido quando o Centro - o ser - o faz. Particularmente pertinente ao trabalho, traz-se a criação do "gaúcho" como uma figura miscigenada. Na medida em que as contribuicoes de povos de fora do escopo europeu tendem a ser pouco reconhecidas, quando se pensa na sua constituicao. Nao só nos seus tracos físicos, mas em seus contumes e hábitos, nota-se o eclipse de tal faceta ao longo da sua narrativa.

Concatenando com a ideia de dominação através do conhecimento, Bourdieu (1996) categoriza a sociologia do conhecimento como um aspecto fundamental dentro da sociologia do poder. Dentro dessa ótica, pode-se compreender que, assim como em outros campos do poder, o campo da produção de conhecimento possui regras próprias de manutenção e de reprodução da estrutura vigente. Esse é um aspecto fundamental dentro da estrutura de dominação.

Em diálogo com tal pensamento, recorre-se ao sociólogo Jessé Souza (2017), em seu livro, A Elite do Atraso, argumenta que todas as ações que os sujeitos tomam acabam por ser influenciadas por ideias e pelo espaço de socialização na qual os mesmos se encontram. $\mathrm{O}$ autor brasileiro (2017) apresenta como ponto fulcral de sua obra a importância do controle das ideias dominantes, pois, em sua visão, possibilita a interpretação e a justificativa do que ocorre, alinhado aos interesses daquele que detém tal produção de conhecimento.

Souza (2017) argumenta que no mundo moderno a dominação deve ser possuir legitimação através do caráter científico, constituindo uma estratégia de dominação mais

5 Usar o termo colonialidade implica reconhecer que várias das estruturas de hierarquizacao se mantém ativas, mesmo após o término formal de grande parte das relacoes coloniais. Segundo Mignolo (2002), a colonialidade representa o lado oculto da modernidade. Se a modernidade é a criação das grandes narrativas racionalistas capazes de explicar o mundo elaboradas pelo iluminismo (KANT, 1784); a colonialidade representa sua faceta oculta, de universalização e submissão dos valores locais aos, supostos, universais (TORRES, 2008). 
simbólica do que material. O prestígio científico controla, na visão do autor, não apenas aquilo que cai sob a égide da academia, mas todos os aspectos presentes da sociedade. Levando em conta a contribuição bourdiana, o autor brasileiro postula que através da reprodução e do monopólio do capital cultural é que a naturalização dos privilégios das Elites dominantes é realizada. Tal lógica pode ser aplicada em escala global ao se considerar o passado colonial. O monopólio dos meios de produção de conhecimento se apresenta como legitimação e justificativa da colonização. Recorre-se a Fanon (1952) e a Said (1978) que em suas obras demonstram como que, através da produção de conhecimento, o colonialismo se encontrava justificado devido pressupostos pseudocientíficos - pautados numa classificação hierárquica que classificavam os não brancos como inerentemente inferiores.

Tal construção classificatória dialoga com os argumentos sobre o próprio Ser, no sentido de essência, elaborados por Torres. Durante seu trabalho o autor argumenta que colonialidade do Ser sugere que ele contrarie sua própria existência. Uma vez que o Ser pode ser entendido como algo opressivo, mas não de maneira igualitária, já que a lógica colonial possui uma violência ontológica, que descrimina povos e populações de formas diferentes. Essas dinâmicas de poder com caráter preferencial acabam marcando o senso comum e a tradição, dando forma, assim, ao movimento da colonialidade do Ser (TORRES, 2008).

Bourdieu encontra na naturalização uma forma de dominação eficiente dentro do campo do poder. Pode-se realizar uma correlação entre a colonialidade do ser - como descrita por Torres - com as estratégias de reprodução existentes promulgadas através do habitus bourdiano uma vez que ele "tende a reproduzir a partir das condições de sua própria produção estratégias objetivamente coerentes e sistemáticas de um método de reprodução" (BOURDIEU, 1996, p. 10, tradução própria).

Torres (2008) argumenta que tais dinâmicas se encontram naturalizadas de tal forma que para muitos autores a existência dessa hierarquia a priori não consiste em um problema em si, visto que essa estrutura serve como ponto de partida. Ao universalizar o começo da história da civilização dentro de suas fronteiras, o Ocidente ofusca a sua participação na criação de mecanismos preferenciais. Seu cânone teórico o coloca no papel de sujeito, de Ser, permitindo que uma fusão de raça e espaço geográfico seja feito, legitimando e justificando opressões sistêmicas (TORRES, 2008).

Juntamente com a importância geográfica para a colonialidade, outro conceito é fundamental é o da colonização do tempo. Como Mignolo (2002) descreve, e as maneiras na qual ele serve como princípio ordenador que relega os lugares não-europeus a uma situação 
anterior dentro da linearidade do progresso, os inferiorizando no ponto de vista dos "donos do tempo".

Ao se hierarquizar as populações - reforçando a noção de que o Ocidente é excepcional e pertencente ao seu próprio nicho superior - no etapismo do desenvolvimento, o ocidente ocupa posição privilegiada nas etapas do progresso, sendo situada como como ponto de chegada dentro dessas evoluções. Pode-se observar como a colonização do tempo também serve de ponto referencial para ordenar o conhecimento, criando um gap entre o conhecimento ocidental - tido como inerentemente superior - e os conhecimentos subordinados (TORRES, 2008).

Souza (2017) argumenta que tal inferiorização não ocorreu apenas durante o período colonial, se apresentando como estratégia de dominação até como política oficial de Estado. $\mathrm{O}$ autor exemplifica com os investimentos realizados pelo governo estadounidense no governo Truman para universalizar o discurso do desenvolvimento e da modernização no pós Segunda Guerra Mundial. Tal discurso situava os EUA como um modelo a ser seguido por todo o planeta e classificava os outros países como realizações incompletas desse exemplo.

O ocultamento da colonialidade do Ser e da colonização do tempo pode ser compreendido em termos bourdianos através da naturalização de princípios dominantes e legitimados, sendo resultado das estratégias de reprodução aplicadas pelas narrativas Eurocêntricas perante o campo do poder internacional.

Quanto ao Brasil, a dominação dos meios de produção de conhecimento está cristalizada de tal forma que existe uma carência das críticas a diversos mitos fundadores dos campos do conhecimento brasileiros. $\mathrm{Na}$ área das ciências humanas pode se encontrar exemplos triunfantes nas obras de Gilberto Freyre e de Sérgio Buarque de Holanda.

Em Casa Grande e Senzala Gilberto Freyre (1957) buscou traçar um nicho para uma identidade nacional compartilhada por todos os brasileiros, partindo de uma herança portuguesa, o autor criou uma cultura única no mundo, a luso-brasileira. Nessa cultura, grandes partes da estrutura social como se conhece hoje existe devido a uma relação entre o escravismo e a herança portuguesa presentes no passado colonial.

Na visão do autor (1957), o "pecado original" cometido durante a colonização do Brasil reside na delegação da tarefa para particulares que eventualmente acabariam por formar as elites locais. Recorre-se a Carvalho (1997) que em sua obra elabora sobre as condições únicas de sua formação e cristalização. Em sua análise o autor demonstra como a única relação entre Estado e elites fora construída através de uma relação particular, aonde a lenta 
expansão do poder estatal penetrou a sociedade englobando as classes via patrimonialismo, clientelismo, coronelismo, populismo, corporativismo.

A visão patrimonialista que Carvalho (1997) oferece uma exploração única da consolidação das elites no período Imperial. A relação patrimonial defendida pelo autor é mais complexa que a simples distribuição de cargos pelo Estado em troca de apoio. Configura-se uma dinâmica em que o governo central encontra-se numa posição precária, com necessidade de delegar a administração local formal às elites do interior. Essa indicação de funções administrativas não passa a constituir uma tarefa burocrática do Estado, uma vez que os locais o realizam sem remuneração monetária.

Para Carvalho, tanto a Coroa Portuguesa, quanto o Estado brasileiro, careciam de recursos suficientes para uma administração plena do território, e para circunvetar tal dificuldade, delegava-se a autoridade o poder privado. Talvez o exemplo mais triunfante possa ser encontrado na criação Guarda Nacional, que o autor categoriza como

\begin{abstract}
“A grande instituição patrimonial que ligou proprietários rurais ao governo (...). é que foi sendo transformada no grande mecanismo patrimonial de cooptação dos proprietários rurais. (...) A escolha democrática dos oficiais, por eleição, foi aos poucos sendo eliminada para que a distribuição de patentes de oficiais correspondesse o melhor possível à hierarquia social e econômica. Em contrapartida, a Guarda colocava nas mãos do senhoriato o controle da população local, institucionalizando as relações de mandismo presentes na elite local" (CARVALHO, 1997, p.6) ${ }^{6}$.
\end{abstract}

Concatenando com o autor, Souza (2017), realizando uma leitura à partir de Freyre, argumenta à falta de instituições reguladoras no interior da então colônia foi basilar para a cristalização das elites se cristalizaram da forma atual, uma vez que possuíam autoridade legal dentro de suas áreas de influência.

Tal cristalização acabou por fortalecer o privatismo, o mandonismo e a ânsia de posse, dentro de tal sociedade não existe justiça superior ao patriarcado, nem poder moral independente, uma vez que a capela consistia numa extensão da casa grande (FREYRE, 1957). Por sua vez, Buarque (1936), em sua obra Raízes do Brasil, cria um arquétipo sobre a própria essência do brasileiro, o homem cordial, o do mulato de sorriso fácil capaz de ascender socialmente através do "jeitinho brasileiro".

Souza (2017) em sua leitura sobre os autores levanta críticas quanto ao que chama de “interpretação dominante" da academia brasileira. O sociólogo argumenta que tal narrativa culturalista se encontra limitada devido aos constrangimentos existentes na época do autores.

6 Para uma discussão conceitual apropriada sobre Mandismo, Coronelismo e Clientelismo, ver Carvalho (1997). 
Delimitar o Brasil a uma herança portuguesa é uma falácia na visão do autor (2017), uma vez que Portugal não teve em seu passado histórico local escravidão concatenada a raça. $\mathrm{O}$ chamado "jeitinho", na visão de Souza (2017), consiste apenas em capital social, ou seja, relações interpessoais que ajudam o sujeito a ascender socialmente, algo que é universal a todas as nações do globo.

Ao contrário de Buarque, que encontra na essência do brasileiro os problemas nacionais, e de Freyre, que as encontra na cultura lusobrasileira, Souza (2017) argumenta que o berço do Brasil se encontra na escravidão e a própria criação de narrativas que situem o país como inerentemente inferior fazem parte do que ele chama de culturalismo racista. $\mathrm{O}$ autor brasileiro (2017) argumenta que a academia brasileira, em sua incepção, se apresenta como uma tentativa de perpetuar o sistema dominante capitalista, assim como naturalizar a posição das elites através do mito da meritocracia. Relembrando Torres (2008) e a colonização do ser, pode-se elaborar que o "ser" brasileiro apresenta sua colonialidade desde de sua formulação, sendo representando como inerentemente inferior à essência europeia e estadounidense.

Para Souza (2017), as elites brasileiras encontraram nas universidades formas de perpetuar e naturalizar a sua dominação como algo inerente ao sistema. O sociólogo classifica o Brasil em basicamente quatro classes sociais de acordo com sua origem histórica e os processos de socialização envolvidos na formação das mesmas, sendo elas: as elites, a classe média, a classe baixa proletária e a ralé dos novos escravos.

As elites, legitimadas pelos ideais liberais ocidentais, necessitavam que outro extrato social naturalizasse e perpetuasse - na forma de habitus - seus mitos fundadores meritocráticos. Para tal, realizou um "pacto" com outra a "outra classe do privilégio", como argumenta Souza (2017), criando assim principal expoente da meritocracia no Brasil: A classe média. O autor (2017) argumenta que a classe média representa uma classe social que possui o capital cultural como seu recurso por excelência. Enquanto as elites apresentam seu poderio econômico como algo inato, a classe média apresenta o conhecimento cientifico como sua moeda naturalizada. Pois, ao contrário das classes dominadas, os filhos da classe média estão inseridos num ambiente onde o estudo é valorizado - tanto pelas famílias, quanto pelas escolas onde são socializadas - podendo se dedicar para o aprendizado em tempo integral.

Dentre os processos de legitimação do conhecimento é fundamental a separação entre quem pode produzir conhecimento e quem não pode. Tal dicotomia é fundamental para o colonialismo e não se baseia na falseabilidade do conhecimento, como exemplifica Said (1979). Fanon (1952), da mesma forma, argumenta que tal divisão é mais profunda, situando aqueles que não podem produzir conhecimento em seu nível essencial como quase 
animalescos, se fazendo do uso de palavras retiradas do bestiário para representar o colonizado. Como um país que encontra na escravidão sua origem, no Brasil não é diferente, Souza (2017) argumenta que a divisão de classes no país pode ser fundamentalmente classificada em duas: as classes de espírito, sendo elas as elites e a classe média. E as classes do corpo, sendo a ralé dos novos escravos e a classe baixa proletária. Estas últimas só possuem como virtude seu trabalho braçal dentro da concepção dominante, seu conhecimento é tido como inerentemente inferior àqueles promulgados pela tradição eurocêntrica.

A criação da academia e dos seus preceitos pelas elites, e sua manutenção e reprodução através da classe média, como previamente exposto, possui papel basilar nas dominações existentes. Dentro dessa visão exploratória povos tidos como inferiores, sejam eles negros, sejam eles povos indígenas, possuem como única virtude seu trabalho braçal. Seus conhecimentos, ainda que desenvolvidos ao longo de uma história ampla, se encontram inerentemente subordinados aos das elites dominantes através de uma divisão realizada e naturalizada através da promulgação de habitus acadêmico, na forma de um culturalismo racista que situa o brasileiro como inerentemente inferior ao europeu e norte americano.

\section{Os Pampas do Poder}

A palavra Pampa vem do quíchua, campo aberto, e é usada para denominar um ecossistema presente a partir do paralelo $30^{\circ}$ na latitude sul do continente americano. Esse bioma, de 750 mil km², transpassa fronteiras do que se convencionou chamar de Brasil, Argentina e Uruguai. (BOLDRINI et al., 2010). Atualmente seu clima é florestal, mas devido ao manejo do ser humano e às interações a qual é submetido, mantem uma vegetação predominantemente campestre (CRUZ e GUADAGNIN, 2010).

Na presente seção se utiliza da noção apreendida por Démetrio Guadagnin e Rafael Cruz (2010) de que o bioma em questão estabelece uma relação mútua com o ser humano. Ao que se divide o período abordado em quatro grandes ciclos de desequilíbrio e estabilidade, provocados pela interferência humana. A partir dessa periodização, se fará uma abordagem histórico-analítica dos três primeiros momentos, interpelando as dinâmicas sociais entre os grupos que ali habitaram, e desses com o ecossistema. Isso se dá como tentativa de compreensão das condições históricas e sociais que correspondentem à disputas de poder analisadas. O que, por sua vez, dará suporte à abordagem da secao que discute as dinamicas de poder no ambito ambito da tecnica agrícola e o papel das elites para seu estabelecimento.

Os primeiros agrupamentos humanos de que se tem registro passaram a habitar os Pampas há 13000 anos (CONSENS, apud CRUZ e GUADAGNIN, 2010), encontrando ali uma paisagem campestre, com baixa ocorrência de matas ciliares e povoada majoritariamente 
por uma megafauna de pastadores. Pontua-se que a interação entre os animais e a vegetação controlava a ocorrência de incêndios através do pisoteio e da redução de biomassa (WALDRAM et al., 2007 apud CRUZ e GUADAGNIN, 2010). A partir de 12000 anos antes do presente (AP) existe uma significativa introdução humana no local, indígenas de tradição Umbu. Caçadores-coletores, trazem com sigo a instrumentalização do fogo, principalmente para as caçadas. É provável, devido à sua interferência no meio, que a Megafauna é extinta por volta de 8000 anos AP. O que coincide com um clima mais quente e estacional, entre 10000 e 4000 anos AP (PILLAR, 2003). Esse aquecimento também possibilita uma maior penetração de vegetação selvática na região.

Portanto, a partir da entrada humana, existe um período de perturbação e adaptação que dura cerca de 4000 anos, seguido de uma fase de estabilidade correspondente a 7600 anos. Nesse novo momento a paisagem é dominada por animais de pequeno porte e hemicriptófitas (plantas medianas) resistentes ao fogo. Ao que se estabelecem variados e heterogêneos grupos indígenas, podendo se apontar os Charruas e Minuanos, notadamente nômades, que basearam seu sustento na caça, pesca e coleta. Há também uma pequena presença de Guaranis, semi-sedentários, praticando agricultura de forma complementar (NUNES, 2014) .

Após esse primeiro ciclo de transformações ambientais, a chegada do Europeu interfere drasticamente no local. Através da introdução de grandes herbívoros e espécies exóticas, há uma grande pressão ecológica, gerando, até mesmo, períodos de intensa seca, notadamente na província de Buenos Aires (DARWIN, 2010). A disseminação desenfreada de equinos e bovinos, que não possuíam predadores especializados, a invasão de vegetacao exótica (cardos e malvas), em conjunto com as queimadas praticadas por estancieiros e indígenas eliminava os capins mais altos. Ainda, certas espécies geófitas nativas, resistentes ao pastoreio e ao pisoteio, voltam a se disseminar amplamente pelos campos. Depois do período mais crítico ocorre certa estabilização no sistema, mas não em todo o bioma, ao que seria seguido por outra fase desestabilizadora, que será tratada a seguir. Para título de explicação, este ciclo é subdivido em três fases.

No âmbito social também, o que ocorre é um período extremamente tribulado. Disputas pelos recursos e modos de vida se sucedem, gerando um processo truncado marcado por relações de múltiplas naturezas, como comércio, violência e assimilação cultural. Nota-se, que as políticas coloniais para com o grupos indígenas não eram uniformes e estáticas. Dependiam dos litígios entre espanhóis, portugueses e nações invasoras, bem como as disposições dos grupos indígenas. Também no período pós-independência, a violência a e paz 
entre os Estados e os diferentes conjuntos ameríndios se dava de forma institucionalizada e auto-interessada (BECHIS, 2005. WEBER, 1998). Assim, se percebe a importância dos estudios fronterizos, ao ressaltar o caráter fluído e poroso das fronteiras que ali se configuravam. As interações socioculturais empreendidas possibilitaram a criação de aspectos extremamente híbridos e particulares (MANDRINI e ORTELLI, 2003).

Nesse processo também se deve levar em conta a participação negra. Trazidos da África forçosamente no intuito de trabalhar nas estâncias e fazendas em regime de escravidão. Imprimiram um papel fundamental, não só econômico, mas sócio-cultural. Sendo a figura do Gaúcho uma expressão da miscigenação entre os negros, os índios e os brancos (CRUZ e GUADAGNIN, 2010). Não que tenha sido um processo pacífico, muito pelo contrário, os processos e as estratégias de dominação empregadas pelo regime escravagista geravam resistências, rebeliões e fugas. Nesse contexto, os quilombos surgem como meio de sobrevivência aos escravos emancipados ou fugidos. Um local onde se agregava conhecimento e espécies domesticadas provenientes da África, com influências indígenas e europeias. Importante notar que tais conjuntos sociais estavam em processo de contínua interferência nos centros de povoação, seja praticando comercio ou influenciando politicamente (PEREIRA, 2014).

Outro fator de grande influição na região são as missões jesuítas, que acabariam por disseminar a propriedade privada no interior da província, fundando diversos núcleos e vilas. (GONZALEZ e VARESE, 1990). Apesar de certa integração de diversas tribos por meio do sincretismo cultural e da conversão religiosa, o projeto jesuítico-guarani termina como se tornou prática costumeira nos pampas: aniquilação e fugas de grande parte dos indígenas para dentro da mata fechada e em direção ao extremo sul. Essa fase se finda tendo os gados asselvajados como centrais para os modos de vida na região, tanto para os indígenas remanescentes das missões, peões em geral, como para as charqueadoras dos estancieiros (ASSUNÇÃO, 2009).

No intuito de consolidar sua fronteira, a partir de 1732 a Coroa Portuguesa passa a conceder lotes de terra a tropeiros e militares de sua confiança. Nesse momento também surge a figura dos posteiros, núcleos familiares que se estabeleciam nos limites entre terras e eram responsáveis por limitar a circulação do gado chimarrão. No entanto, a partir de 1870 com a chegada do arame inglês, os mesmos perdem sua função para um simples alambrado, sendo obrigados a se dedicar a outros ofícios, geralmente migrando para áreas urbanas (FONTOURA, 2014). Esse momento coincide com o início de outra fase de estabilização na composição dos campos,tem início devido ao maior cercamento de propriedades e o manejo 
de lotação associado com queimadas. Percebe-se a concentração paulatina da propriedade, devido a políticas estatais diversas, submetendo a indígenas, negros e grande parte dos mestiços e criollos dominação sob a égide das, ainda em formação, elites locais. (GONZALEZ e VARESE, 1990).

Em meados do século XIX, a imigração europeia massiva passa a ser buscada, tanto para ocupação de terras resolutas, como projeto civilizatório. Ao que se distinguia da grande propriedade escravagista, o modelo implementado visava a pequena propriedade familiar. Através do processo de uma naturalização que estabelecia o negro como inapto ao trabalho livre, criou-se um receio da imagem de uma sociedade arcaica. Assim, através das políticas de embranquecimento da população, incentivou-se a migração europeia e seu estabelecimento, custeando, muitas vezes, a viagem e doando terras. (RODRIGUES, 1961. SEYFERTH, 2002. CURI, 2011). Por exemplo, havia a possibilidade de compra de terras por parte do imigrante, o que era negado ao lavrador nacional, muito antes da Lei de Terras de 1850 (FONTOURA, 2014).

Esse processo não se dá de forma simples e homogênea. A exemplo das políticas imperiais, que em seu movimento de dominação naturalizavam e reproduziam classificações hierarquizantes entre os próprios povos europeus, designando tipos desejados. Outro ponto, o isolacionismo praticado por certas colônias de imigrantes e a lenta incorporação à sociedade brasileira gerava uma preocupação recorrente entre sua elite política e intelectual (SEYFERTH, 2002). Ao que se compreende que os grupos familiares que aqui se instalaram trouxeram consigo traços culturais destoantes da expectativa. Leva-se em conta, ainda, que grande parte dos mesmos era proveniente dos substratos mais pobres da população europeia. Esses novos grupos passam a aplicar técnicas e cultivos europeus, muitas delas tradicionais. Tendo em vista o apontado por Radomsky (2011), não só aspectos entendidos como modernos, mas também tradicionais, podem ser percebidos nas sociedades centrais.

Em retrospecto, o período abordado engloba cerca 400 anos, com uma fase de ajuste e outra de estabilização. Ao que se vale comparar com o ciclo anterior, de 12000 anos. É a partir da segunda metade do século XX que o segundo ciclo começa a entrar em crise devido às pressões da política fundiária. O modelo de lotação corrente ultrapassa seu limite, gerando degradação ambiental e perda da produtividade bovina. Ao que traria um terceiro ciclo de transformações ambientais. Responsável não só por impactar o bioma, mas por substituir $60 \%$ do sistema de campo através da atividades agrícolas industriais. Descaracterizando completamente seu ecossistema em 60 anos (CRUZ e GUDAGNIN, 2010). 
Após o final da Segunda Guerra Mundial, seriam empreendidas inciativas modernizantes por meio de intervenções Estatais e de fundações internacionais. Devido às correlações políticas vigentes, a "modernização conservadora" se dá através de políticas agrárias, transformando a base científico-tecnológica da agricultura. Os profissionais das ciências agrárias teriam a tarefa de transmitir as inovações da tecnologia "moderna", em vias de gerar desenvolvimento (FROEHLICH, 2010. LEAL E BRAGA, 1993). Esse movimento, de implementação de inovações da indústria mecânica e química na esfera rural, ficaria conhecido como revolução verde, responsável por intensificar capitalização das relações nesse local (CRUZ e GUDAGNIN, 2010). São introduzidos cultivos exóticos para "melhoramento de pastagem" bovina e exploração da sivicultura, aliado ao crescimento do cultivo de grãos. Ao que diminui e fragmenta os habitats naturais, ocasionando perda de biodiversidade da flora e da fauna regional, inclusive expondo certas espécies à extinção. Tal cenário vem a agravar concentração de renda e falta de autonomia de certos setores agrários, gerando exclusão social na região (FROEHLICH, 2010).

Portanto, o que se percebe é que a parte sul do estado

mantém até o século XX uma sociedade agrária rentista, onde a produção da riqueza se dá fundamentalmente no campo, o trabalho humano pouco gera mais valor, e o aumento da produção depende necessariamente das condições naturais (pastagens e variações do clima) e da produção em escala. Ou seja, do aumento da área de campo com baixo investimento, ainda que contasse com o melhoramento genético do rebanho. Desta forma, a cidade se limita a administração de uma atividade pouco diferenciada e de baixa distribuição de tarefas e da riqueza produzida. (FONTOURA, 2014 , p. 34).

Ainda, historicamente, se configura uma sociedade rural de médias e grandes propriedades, caracterizada pela contínua concentração do capital (financeiro, cultural, dos meios de produção etc), deveras ligado ao fortalecimento dos regimes de monocultivo, direcionados para o mercado exterior. Tendo em vista que em certo momento, as políticas de colonização e embranquecimento, geraram maior distribuição das terras. No que há uma relativa quantidade de composições de agricultura familiar, que apesar de, por vezes, manterem características da agroindústria, são mais heterogêneas. Algo que vêm se perdendo devido à interferência globalizante.

O que se nota, ainda, é que o investimento capitalista em técnica e infraestrutura não tende a ser promovido pela elite local, mas tem origem externa. Ao passo que a elite latifundiária deixa de ser rentista no campo e se torna rentista na cidade, grandes empresas passam a concentrar posse da terra. Esse processo é concatenado a uma vercatilização da cadeia de produção e do beneficiamento, há especialização e enxugamento da mão de obra. Portanto, há dificuldade da população rural e de pequenas cidades em se integrar no processo 
(FONTOURA, 2014). No que diz respeito aos ciclos ambientais, é apontado por Démetrio Guadagnin e Rafael Cruz (2010) que estaríamos adentrando numa quarta etapa, ocasionado pelas mudanças climáticas induzidas pelo ser humano. Ao que se prospecta uma tendência de aquecimento, acompanhado sazonalização das chuvas, havendo assim, a assemelhação do bioma pampa com as características savanais.

A partir do panorama aqui delineado se percebe a ascensão do modelo do agronegócio e a sistematização técnico-científica que lhe dá suporte. No entanto, se é servindo aos interesses de grupos poderosos que tal discurso é naturalizado no regime de verdade, a sua aceitação e reprodução na forma do habitus bourdiano advém de específicas estratégias de dominação sociais políticas, econômicas, intelectuais e culturais (JACKSON e CARTER, 2007). Assim, pode se concatenar diversos elementos que se consolidam no período final do século XX, como o êxodo rural massivo (MEGA, 2008) os ajustes macro-estruturais promovidos pelo Banco Mundial e o Fundo Monetário Internacional (ALIMONDA, 2009) e a ascensão do pensamento neoliberal e seu alinhamento ao discurso de progresso (DUPAS, 2006). Ainda as descobertas cientificas no ramo da biologia molecular (PFRIMER e BARBOSA JÚNIOR, 2017) e a informação instantânea e monopolizada, possibilitando que transnacionais tenham acesso a territórios longínquos. (HAERBAERT e PORTOGONÇALVES, 2006).

\section{A Modernizacao Conservadora}

Entende-se que a atual configuração rural brasileira é fruto de determinado processo histórico, tendo a colonização como evento de grande importância. Segundo Daniela Pacífico (2009) desde tal momento a elite agrária vem impondo o modelo do latifúndio através da dominação social, política e econômica. O mesmo se tornou reconhecido socialmente, ditando a política agrícola. Somado a esse processo explorador e escravocrata, a desigualdade social e o patrimonialismo agem no sentido de marginalizar pequenos produtores familiares (WEDIG, 2009).

O que se percebe é que, com a industrialização da agricultura, a sobrevivência, a identidade e o pertencimento daquele que trabalha na terra sofreu nova ameaça. Através da introdução de um pacote tecnológico (maquinário, sementes, insumos, agrotóxicos, etc) favorecedor da monocultura, a elite agrária, dotada de propriedades extensas, elevado poder aquisitivo e receptora de financiamentos estatais, se mantém como grande beneficiária (PACÍFICO, 2009). 
Há uma transformação da agricultura, que passa a ser entendida como uma simples etapa da produção. Com o uso intensivo de instrumentos externos à propriedade (e até, ao país) o agricultor não possui controle dos insumos de que necessita. Cabendo-se salientar que não só os recursos naturais, mas toda a cadeia produtiva, passam por um processo de concentração (PACÍFICO, 2009) sendo submetidos à lógica capitalista.

Como base de tal mudança tecnológica, está o discurso que alia progresso e modernidade ao modelo homogeneizador. Imprimindo ao campo um sinônimo de atraso em contraste aos centros urbanos, local de oportunidades. A própria mecanização do processo viria a tornar grande parte da mão-de-obra rural desnecessária. Como resultado, o final dos anos 1960 e toda a década de 1970 presenciam um êxodo rural massivo. Por fim, às famílias que permaneceram no campo, coube aderir ao novo modelo ou serem continuamente marginalizados da produção (WEDIG, 2009).

Para melhor entender o papel decisivo do aparelho estatal na fomentação dessa industrialização, faz-se útil recorrer ao que Daniela Pacífico (2009) nomeia tripé do desenvolvimento: "o fomento à pesquisa, à extensão e ao crédito rural" (p.3). Estando integrado a um processo de transformação capitalista da economia brasileira (DAL SOGLIO et al, 2009), desde a década de 1930, no governo de Getúlio Vargas, implementavam-se políticas no sentido de promover a industrialização brasileira. Mas é só com o governo de Jucelino Kubitschek (1958-1961) que o modelo toma forma. Os processo de produção e comercialização passam a ser impactados pelas alterações técnica e tecnológicas, dando início aos complexos agroindustriais (DAL SOGLIO et al, 2009).

Nesse novo quadro, pautado pela pesquisa, extensão e crédito subsidiado, são direcionados vultuosos investimentos públicos. Tendo como referência valores produtivistas, forma-se de uma ampla infraestrutura de pesquisa e recursos humanos, sem que se considerem aspectos sociais, culturais e ecológicos. Já a extensão rural, teve como papel afirmar tais valores, ligando pesquisadores e produtores na transferência das tecnologias desenvolvidas por institutos como a EMBRAPA. Salienta-se que os objetivos das pesquisas em questão, mesmo que financiadas por fundos públicos, eram, em geral, orientados para a agricultura industrializada, sofrendo influência direta dos grandes proprietários. Por fim, o crédito rural dá tom à época aura da modernização da agricultura. Na década de 1960 é criado o Sistema Nacional de Crédito Rural, em vias de facilitar a disseminação das novas tecnologias.

De forma geral, a industrialização do meio rural e as políticas públicas condizentes vem a impactar negativamente pequenos produtores, não se adequando a suas demandas 
produtivas e agravando seu empobrecimento. Uma vez que demandava elevados custos e uma profunda mudança de padrões culturais, ínfima parte dos pequenos produtores se adequariam ao novo processo produtivo (WEDIG, 2009). Portanto, mesmo que o processo abordado tenha gerado um aumento de produtividade, o enfoque no crescimento econômico per se, gerou efeitos danosos para parte significativa da população (DAL SOGLIO et al, 2009).

Esse processo possui implicações até atualidade, ao que se nota na criação e aplicação internacional do conceito de desenvolvimento, estreitamente relacionado ao ímpeto civilizatório modernizante. Escobar (2009) postula que o desenvolvimento é um projeto econômico e cultural, subordinando os demais conhecimentos à princípios ocidentais, frutos da particular experiências de modernidade europeia. Se percebendo uma intensa consequência no espaço rural, como já abordado anteriormente. Todavia, esse é um quadro de certame, visto que certos atores exercem sua agência, resistindo aos modelos de desenvolvimento e propondo alternativas (DAL SOGLIO al, 2009). Tal é o caso da agroecologia. Contrapondose à racionalidade econômica dominante e valorizando seu papel socioambiental, essa critica severamente os paradigmas epistemológicos vigentes. E como apontam Ricardo Borsatto e Maristela Simões (2013), busca sua consolidação como campo científico. Tendo em conta que a ciência é uma arena de disputas (BOURDIEU, 2008), a agroecologia questiona os valores dominantes e busca transformá-los. A partir da crítica ao autoritarismo da ciência positivista, há uma legitimação dos saberes tradicionais e sua aplicabilidade (BORSATTO e CARMO, 2012).

A partir do abordado, nota-se as dinâmicas disputas entre os atores participantes dos pampas. Leva-se em conta suas relações históricas de poder e saber, o que definiu o discurso no âmbito agrário, obedecendo às regras que viriam por reafirmar regimes de verdades em determinados momentos. Seguindo, procura-se abordar tais disputas na atualidade. Enquanto que o discurso do agronegócio tem como referência a produtividade e o impacto econômico, a agroecologia tende a subverter a própria noção de positividade nesses argumentos, fundamentando suas práticas na sustentabilidade ecológica e na participação ativa de sujeitos marginalizados. Delineia-se aqui uma disputa entre quais práticas irão se estabelecer como hegemônicas em determinado campo. Como apontado por Bourdieu, campo "é o lócus onde se trava uma luta concorrencial entre atores em torno de interesses específicos que caracterizam a área em questão" (1983, p. 19). Que é o que se procurará estudar, o embate entre as concepções, principalmente agronegócio e agroecologia, no campo da agricultura praticada ao longo dos pampas. 


\section{O caso Gaúcho}

Tendo como suporte o extenso panorama teórico apresentado, faz-se possível abordar a realidade da parcela pampeana do Rio Grande do Sul. Fazendo-se possível identificar o capital cultural atravessando as mais variadas disputas, sendo aspecto fulcral dentro da revolução verde. Considera-se a pecuária extensiva como basilar da economia pampeana, primeiro, com o comércio do gado, depois, através o charque. Em ambos os momentos fez-se notória a concentração de múltiplos recursos de poder por parte de certa elite, principalmente no que diz respeito à terra. Todavia, ínumeros são os casos em que tal elite utilizou de seu capital em diferentes arenas e de forma homóloga. Notadamente, na política institucional, seja através de ações efetivas ou pela promulgação de leis.

A partir do aporte anteriormente citado carcteriza-se a dinâmica do poder como Coronelismo. Por um longo período, através de um sistema de troca de favores: os estancieiros garantiam o fortalecimento do Estado ao mesmo tempo em que possuiam autonomia extra legal, agindo em vias de expropriar propriedades e retirar vidas. Por outro lado, a ligacao entre os peoes e os estancieiros foi configurada por uma dependência ilusória, em que, muitas vezes, trabalhava-se por moradia. Também havia a tática de endividamento das camadas mais pobres, que iria se sentir moralmente atrelado à estância. Ainda, muitos foram os peões gaúchos contratados em exércitos particulares que viriam a imprimir batalhas de exclusivo interesse da elite. (PICCIN, 2012).

A partir do aporte anteriormente citado caracteriza-se a dinâmica do poder como Coronelismo. Por um longo período, através de um sistema de troca de favores: os estancieiros garantiam o fortalecimento do Estado ao mesmo tempo em que possuíam autonomia extralegal, agindo em vias de expropriar propriedades e retirar vidas. Por outro lado, a ligação entre os peões e os estancieiros foi configurada por uma dependência ilusória, em que, muitas vezes, trabalhava-se por moradia. Também havia a tática de endividamento das camadas mais pobres, que iria se sentir moralmente atrelado à estância. Ainda, muitos foram os peões gaúchos contratados em exércitos particulares que viriam a imprimir batalhas de exclusivo interesse da elite. (PICCIN, 2012).

Da mesma forma, quando levada em consideração a história recente, a reprodução e naturalização de tal dinâmica se demonstra clara. As políticas de incentivo à modernização agrária vieram a abarcar os interesses dos grupos dirigentes historicamente abastados. Como a lei do boi, que perdurou entre 1968 e, reservava 50\% das vagas de Agronomia e Medicina Veterinária aos trabalhadores rurais, o que viria a beneficiar exclusivamente os filhos de 
grandes proprietários que podiam se dedicar aos estudos (MAGALHÃES, 2017). Ainda, o aporte técnico considerado, que basearia a transformação produtiva em questão, teve como referência objetivos e valores que privilegiam grandes produtores. Tais medidas vieram a garantir aos mesmos uma inserção vantajosa não só no mercado nacional, como internacional. O que se nota, todavia, é que essas transformações podem não se limitar a elite local, favorecendo oligopólios transnacionais com ainda mais capital.

Como demonstrado anteriormente a naturalização e reprodução dos saberes válidos corresponde aos saberes que concatenam com a visão eurocêntrica vigente. Concatenando com Souza (2017), a transformação de política local, para política sancionada pelo Estado, promulgada pelo do discurso do desenvolvimento pode ser compreendida como a maior prova da cristalização do conhecimento eurocêntrico como um habitus dentro de seu campus automizado (BOURDIEU, 1996).

A crescente dominação simbólica presente pelas formulações acadêmicas supre o papel de alinhamento das verdades locais - inerentemente inferiores - com aquelas do centro (MIGNOLO, 2002). Uma vez que a própria formação do conhecimento científico, e de sua racionalidade, é apresentada como universalista, se torna natural que as abordagens que se alegam técnicas não considerem o locus geográfico originário das teorias que as originaram.

A crescente capitalização e os lucros marginais cada vez mais elevados como apontados por Cruz e Gudagnin (2010) suprem as necessidades das elites locais brasileiras por acumulação de capital econômico rápido (SOUZA, 2017). Como consequência os impactos sócioambientais das ações dos estancieiros e grandes agricultores é deixado de lado em prol de lucros imediatos.

\section{Conclusões}

O presente artigo constituiu num esforço inicial investigativo sobre as origens da elites agrárias do pampas gaúchos e assim como os motivos na qual o processo da modernização conservadora se empregou do conhecimento eurocêntrico ocidental.

A fim da resolução da problemática proposta se empregou como metodologia o método bourdiano, assim como as teorias pos-coloniais e decoloniais. Pierre Bourdieu apresenta como seu método teórico um modelo análitco particular e extremamente eficiente para o estudo do grupo escolhido, porém é necessário situar geograficamente sua abordagem. Considerando as condições singulares das elites no Brasil, dado a sua condição como um país marcado pelo colonialismo e pela escravidão, os grupos dirigentes locais possui características extremamente diferente dos grupos franceses. Portanto, reconhecendo as limitações do método bourdiano, os pesquisadores optaram por suplantar tais deficiências 
através do emprego da literatura latino-americana decolonial, uma vez que a mesma apresenta ferramentas analíticas únicas ao analisar as sociedades que possuem o colonialismo como passado histórico.

Se utilizando principalmente do conceito bourdiano de capital cultural e de habitus, empregados conjuntamente com a geopolítica do conhecimento decolonial, o presente projeto buscou explicar a valorização do conhecimento eurocêntrico em detrimento dos saberes locais. Como resposta o artigo encontra que tal valorização se encontra enraizado na própria criação das elites locais e na construção de uma confluência entre aquilo que é um conhecimento válido e útil em detrimento do que não é.

Fundamental a tal classificação constitui a cristalização e separação dos expoentes de conhecimentos. Devido as origens históricas coloniais e escravistas do país tal secessão se utiliza da raça como codificação, naturalizando o conhecimento europeu como inerentemente superior. Tal naturalização possui um proposito, a dominação e acumulação de capitais valorizado socialmente pelas chamadas "classes do privilégio".

A academia não se demonstra isenta de tal processo de dominação, muito pelo contrário, em sua fundação a academia existe como uma defensora das ideias das elites. $\mathrm{O}$ próprio "Ser" brasileiro se demonstra colonizado em sua essência, segundo a academia brasileira tradicional. No âmbito da elites gaúchas não se mostra diferente, o campo do conhecimento apresenta sua automização realizada de acordo com as ideias eurocêntricas, com suas ideias cristalizadas e reproduzidas de acordo com sua confluência com tal conhecimento cientifico.

A chamada revolução verde, como exposta no artigo, não foi realizada com base no conhecimento da melhor forma de cultivo da terra, mas com base nas metodologias eurocêntricas desenvolvidas e otimizadas para sua própria forma de plantio. Os saberes locais em tal processo, foram marginalizados devido a sua posição de marginal do campo do conhecimento.

A via de conclusão, a metodologia desenvolvida pelo presente artigo se mostrou satisfatória para a resolução da problemática proposta, porém uma vez elaborada, seria de interesse acadêmico realizar pesquisas em locus para fortalecer o argumentação com dados empíricos. De particular interesse seria realizar um estudo comparativo das metodologias aplicadas e apresentadas como hegemônicas dentro dos campos de conhecimento locais, como universidades e cursos. 


\section{Referências}

DAL SOGLIO, Fábio et al. Agricultura e sustentabilidade. Universidade Aberta do Brasil UAB/UFRGS e Curso de GraduaçãoTecnológica - Planejamento e Gestão para o Desenvolvimento Rural da SEAD/UFRGS. Porto Alegre: Editora da UFRGS, 2009.

BECHIS, Martha. "Fuerzas indígenas en la política criolla del siglo XIX” in GOLDMAN, Noemi y SALVATORE, Ricardo (comp.). Caudillismos rioplatenses: nuevas miradas a un viejo problema. Buenos Aires: Eudeba, 2005.

BOLDRINI, I. I.; FERREIRA, P. M. A.; ANDRADE, B. O.; SCHNEIDER, A.A.; SETUBAL, R. B.; TREVISAN, R; FREITAS, E.M. Bioma Pampa: diversidade florística e fisionômica. Porto Alegre, editora Pallotti, 2010.

BORSATTO, Ricardo Serra. CARMO, Maristela Simões do. Agroecologia e sua epistemologia. Interciencia, v.37, n.9, p. 711-716, 2012.

BORSATTO, Ricardo Serra; CARMO, Maristela Simões do. A Agroecologia como um campo científico. Revista Brasileira de Agroecologia, [S.1.], v. 8, n. 2, aug. 2013.

BOURDIEU, P. Homo academicus. Madrid: Siglo XXI, 2008.

BOURDIEU, Pierre. As condições sociais da circulação internacional das idéias. Enfoques, [S.1.], v. 1, n. 1, p. 4-15, jan. 2002. Disponível em: <http://www.enfoques.ifcs.ufrj.br/ojs/index.php/enfoques/article/view/12>. Acesso em: 31 ago. 2018.

BOURDIEU, Pierre. La Nobleza de Estado. [S.1.: s.n.], 1996. 499 p.

BOURDIEU, Pierre. Questões de Sociologia. Tradução de Jeni Vastsman. Rio de Janeiro: Marco Zero, 1983.

BUARQUE, Sérgio. Raizes do Brasil. São Paulo: Companhia das Letras, 2001.

CARVALHO, José Murilo de. Mandonismo, Coronelismo, Clientelismo: Uma Discussão Conceitual. Dados, Rio de Janeiro , v. 40, n. 2, p. , 1997 . Disponível em $<$ http://www.scielo.br/scielo.php?script=sci_arttext\&pid=S001152581997000200003\&lng=pt\&nrm=iso>. acessos em 27 nov. 2018. http://dx.doi.org/10.1590/S0011-52581997000200003.

COSTA, Sérgio. Dois Atlânticos: teoria social, anti-racismo, cosmopolitismo, Belo Horizonte: Editora UFMG. 2016.

CRUZ, Rafael Cabra. GUADAGNIN, Demétrio Luiz. Uma pequena história ambiental do Pampa: proposta de uma abordagem baseada na relação entre perturbação e mudança. in Costa B.P., Quoos J.H., Dickel M.A.G. (Eds.), A Sustentabilidade da Região da CampanhaRS: Práticas e Teorias a Respeito das Relações entre Ambiente, Sociedade, Cultura e Políticas Públicas. P. 155-179. UFSM, Santa Maria. 2010. 
CURI, Alcides Beretta. La inmigración europea en la formación del tejido empresarial Uruguay en la región (1870-1900). Studi Emigrazione XVIII, No 184. 675-695. 2011.

DARWIN, C. The Voyage of the Beagle. Los Angeles: Web Book Publ?., 2010.

DE SAINT MARTIN, Monique. DA REPRODUÇÃO ÀS RECOMPOSIÇÕES DAS ELITES:AS ELITES ADMINISTRATIVAS, ECONÔMICAS E POLÍTICAS NA FRANÇA. Tomo, Sergipe, v. 13, n. 13, p. 43-74, jan. 2008. Disponível em: <https://seer.ufs.br/index.php/tomo/article/view/467>. Acesso em: 31 ago. 2018.

DUPAS, Gilberto. O mito do progresso: ou progresso como ideologia. São Paulo, UNESP. 2006.

ESCOBAR, Arthuro. La invención del Tercer Mundo: Construcción y deconstrucción del desarrollo. El perro y la rana, 2007.

ESCOBAR, Arturo. América Latina en Movimiento No. 445, ALAI, Quito, junio 2009

FANON, Frantz [1963]. Peles Negras, Máscaras Brancas. New York: Grove Press, 1994.

FLEURY, Lorena Cândido. Multiplos olhares, uma questao: repensando a agricultura e o desenvolvimento. In DAL SOGLIO, Fábio et al. Agricultura e sustentabilidade. UAB e SEAD/UFRGS. Porto Alegre: Editora da UFRGS, 2009.

FREYRE, Gilberto. Casa Grande e senzala. Lisboa: Livros do Brasil, 1957.

FROEHLICH, José Marcos. A novelesca reforma curricular das ciências agrárias e a sustentabilidade: novas demandas, velhos problemas. Revista Brasileira de Agroecologia Rev. Bras. de Agroecologia. 5(2): 3-15. 2010.

FONTOURA, Luiz Fernando Mazzini. A modernização da agricultura e a urbanização incompleta. CaderNAU-Cadernos do Núcleo de Análises Urbanas, v.7, n. 1, 2014.

GONZÁLES, Shirley Rodríguez. PEREIRA,Viviane Camejo, DAL SOLGIO, Fábio Kessler. A Perspectiva Orientada ao Ator em estudos sobre Desenvolvimento Rural.. Perspectivas Rurales. Nueva época, Año 13, º 25, ISSN: 1409-3251, 2014.

GONZÁLEZ, luis Rodolfo. VARESE, Susana Rodríguez. Guaraníes y Paisanos. Montevídeo: Nuestras Raices 3, 1990.

Jackson, N., \& Carter, P. Rethinking Organisatonal Behaviuor A Poststructuralist Framework. Essex, England: Pearson Education Limited. 2007.

KANT, Immanuel An answer to the question: 'What is Enlightenment?'. (tr.: Mary Gregor). Em: KANT. Practical philosophy. (Org. Mary GREGOR). Cambridge: Cambridge U.P.,1996. [1784].

LEAL, M. G. F. \& BRAGA, G. M. Extensão Rural e formação profissional: um estudo preliminar. Cadernos de administração rural. Lavras: ESAL, 5(1-2): 27-38. 1993. 
MANDRINI, Raul. ORTELLI, Sara. "Una frontera permeable: Los indígenas pampeanos y el mundo rioplatense en el siglo XVIII" GUTIERREZ, H. NAXARA, R. C. LOPES, M. A. S. (orgs.); Fronteiras: paisagens, personagens, identidades; Franca: UNESP: São Paulo: Olho d'água, 2003.

MEGA, L. A. Mudanças causadas pelo programa de transferência direta de renda, bolsa família, aos beneficiários de Santa Vitória do Palmar - RS. Dissertação de Mestrado apresentada ao Curso de Serviço Social da Universidade Católica de Pelotas. UCPEL, Pelotas, 2008.

MIGNOLO, Walter D. Colonialidade do poder, eurocentrismo e América Latina.Em: Lander, E. A colonialidade do saber: eurocentrismo e ciências sociais. Perspectivas latinoamericanas.Buenos Aires, CLACSO. 2005.

MIGNOLO, Walter. "Geopolitica del conocimiento y diferencia colonial” Traducción del articulo Geopolitics of knowledge and colonial difference (The South Atlantic Quarterly 101 (2): 57-96, 2002) Neves. $2^{a}$ ed. Rio de Janeiro: Forense-Universitária, 1986.

NUNES, R. B.Charruas e Guarani-missioneiros no Uruguai e no sul do Brasil: a etnicidade enquanto experiência. In: 29a Reunião Brasileira de Antropologia, 2014, Natal - RN. Anais da 29a Reunião Brasileira de Antropologia, 2014.

PACÍFICO, Daniela A. História da modernizacao da agricultura:umnconto de muitas facetas. In DAL SOGLIO, Fábio et al. Agricultura e sustentabilidade. Porto Alegre: Editora da UFRGS, 2009.

PEREIRA, Amilcar Araujo (Org). Educação das relações étnico-raciais no Brasil: trabalhando com histórias e culturas africanas e afro-brasileiras nas salas de aula. Brasília : Fundação Vale, 2014.

PFRIMER, Matheus Hoffmann. BARBOSA JUNIOR, Ricardo César. Neo-AgroColonialism, Control over Life, and Imposed Spatio-Temporalities. Contexto Internacional vol. 39(1) Jan/Apr 2017

PICCIN, M. B. Os Senhores da Terra e da Guerra do Rio Grande do Sul: um estudo sobre as estratégias de reprodução social do patronato rural estancieiro. Tese de Doutorado do Programa de Pós-Graduação em Ciências Sociais da Universidade Estadual de Campinas, SP. 2012.

PILLAR, V.D. Dinâmica da Expansão Florestal em Mosaicos de Floresta e Campos no Sul do Brasil. In: Claudino-Sales, V. (org.) Ecossistemas Brasileiros: Manejo e Conservação. Fortaleza: Expressão Gráfica e Editora, p.209-216. 2003.

QUIJANO, Anibal. Colonialidade do poder, Eurocentrismo e América Latina. A colonialidade do saber: eurocentrismo e ciências sociais. Perspectivas latino-americanas. Buenos Aires. CLACSO, Consejo Latinoamericano de Ciencias Sociales. 2005.

RADOMSKY, Guilherme Francisco Waterloo. Desenvolvimento, pós-estruturalismo e pósdesenvolvimento: a crítica da modernidade e a emergência de "modernidades" alternativas. In: Revista Brasileira de Ciências Sociais. vol.26.no.74. São Paulo, fev. 2011. 
RODRIGUES, José Honório. Brasil e África: outro horizonte; relações e política brasileiroafricana. Rio de Janeiro: Civilização Brasileira. 1961.

SAID, Edward [1978]. Orientalismo: O Oriente como invenção do Ocidente. São Paulo: Companhia das Letras, 2007.

SANTEIRO, T. V. Criatividade em psicanálise: produção científica internacional (19961998). Psicologia: Teoria e Prática, São Paulo, v. 2, n. 2, p. 43-59, jul./dez. 2000. (Artigo em Periódico Físico)

SANTOS, Boaventura de Sousa; MENESES, Maria Paula. (Orgs.) Epistemologias do Sul. São. Paulo; Editora Cortez. 2010.

SANTOS, Boaventura de Sousa; MENESES, Maria Paula; NUNES, João Arriscado. Introdução: para ampliar o cânone da ciência: a diversidade epistemológica do mundo, in B. S. Santos (org.), Semear outras soluções. Porto. Afrontamento, 23-101.2004

SETH, Sanjay. Post-colonial Theory and International Relations: A critical introduction. Routledge 2013.

SEYFERTH, Giralda. Colonização, imigração e a questão racial no Brasil. Revista USP, São Paulo, n.53, p. 117-149, março/maio. 2002.

SOUZA, Jessé. A elite do atraso: da escravidão à Lava Jato. Leya: Rio de Janeiro. 2017.

TORRES, Nelson Maldonado. A topologia do Ser e a geopolítica do conhecimento: Modernidade, império e colonialidade. Revista Crítica de Ciências Sociais, [S.1.], n. 80, p. 71-114, jan. 2008. Disponível em: <https://journals.openedition.org/rccs/695>. Acesso em: 31 ago. 2018.

WALDRAM, M.S.; BOND, W.J.; STOCK, W.D. Ecological Engineering by a MegaGrazer: White Rhino Impacts on a South African Savanna. Ecosystems, v.11, n.1. p.101112. 2007.

WEBER, David J. "Borbones y bárbaros. Centro y periferia en la reformulación de la política de España hacia los indígenas no sometidos”. . Anuario IEHS; Tandil, nº 13, 1998.

WEDIG, Josiane Carine. Reflexoes socioculturais acerca do mundo rural. in DAL SOGLIO, Fábio et al. Agricultura e sustentabilidade. Porto Alegre: Editora da UFRGS, 2009. 